\title{
Design and Realization Wilkinson Power Divider at Frequency 2400MHz for Radar S-Band
}

\author{
Taufiqqurrachman ${ }^{1}$, Deni Permana Kurniadi ${ }^{2}$ \\ ${ }^{1,2}$ (Research Center for Electronics and Telecommunication - Indonesian Institute of Sciencies (LIPI), LIPI- \\ Campus, Sangkuriang Street, Building 20-4 ${ }^{\text {th }}$ floors, Cisitu, Bandung - Indonesia 40135)
}

\begin{abstract}
This paper presents design and realization of 2-way Wilkinson Power Dividers (WPD) at frequency $2400 \mathrm{MHz}$ for Radar S-Band. Power dividers in radar S-Band used for divide the output power from oscillator where used for the mixer of transmitter and receiver section. The 2-way WPD used Wilkinson configuration where consist of two quarter-wavelength transmission line ( $\lambda \mathrm{g} / 4)$ and one resistor chip between the both output ports. Design of the 2-way WPD presents by simulation result with ADS2011.10 and have been implemented using Roger Duroid 5880 substrate. The simulation and measurement result contains graph of insertion loss, voltage standing wave ratio (VSWR) or return loss, and isolation between the both output ports. The measurement result of the 2way WPD indicating a good performance than the 2-way power dividers with wideband that currently used and its suitable to use at radar S-band for divide the output power from oscillator.
\end{abstract}

Keywords - Power Dividers, Radar S-Band, Wilkinson

\section{Introduction}

Power dividers are one of microwave component that have function for divide the power signal input to several the output power signal. General configuration of the power dividers is used Wilkinson Power Divider (WPD) because this configuration has a good parameter like lossless (if matched at the all port) and high isolation between the outputs port [1]. In radar system, the power dividers used for divide the power signal from the local oscillator to the mixer of transmitter and receiver. So the power divider should have a little power loss when dividing the power of the local oscillator not to interfere with the performance of the overall radar system. Currently the radar system using the wideband power dividers that operates at frequencies between $2-18 \mathrm{GHz}$ where the insertion loss result at $2400 \mathrm{MHz}$ frequency center about $-3.4 \mathrm{~dB}$. While the local oscillator from the radar system has designed at frequency center $2400 \mathrm{MHz}$ (S-Band). In order to solve this problem, the 2-way WPD at $2400 \mathrm{MHz}$ frequency center has designed and realized in this paper.

\section{Design Methodology}

The 2-way WPD usually employ quarter-wavelength transmission line $(\lambda \mathrm{g} / 4)$ section at the design center frequency and Wilkinson power consists of two quarter-wavelength line segments at the center frequency $\left(f_{c}\right)$ with characteristic impedance $\sqrt{ } 2 * Z_{o}$, and a $2 * Z_{o}$ lumped resistor connected between the output ports [2]. A popular basic configuration of the 2-way WPD is often made in microstrip or stripline form as depicted in Fig. 1a, and the corresponding transmission line circuit is given in Fig. 1b [3].

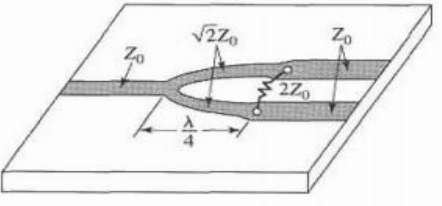

(a)

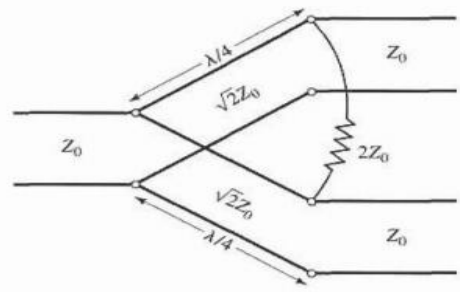

(b)

Fig. 1 The Wilkinson Power Divider.

(a). An equal-split Wilkinson power divider in microstrip form

(b). Equivalent transmission line circuit

The 2-way WPD with $2400 \mathrm{MHz}$ frequency center $\left(\mathrm{f}_{\mathrm{c}}\right), \mathrm{Z}_{\mathrm{o}}=50 \Omega$ will be designed and fabricated on a $0.787 \mathrm{~mm}$ thick Roger Duroid 5880 substrate which has relative permittivity of 2.2, the dissipation factor is 0.0009 and conductor thickness of $35 \mu \mathrm{m}$. The smallest insertion loss result depends on designing of the width of $\lambda \mathrm{g} / 4$ section $(\mathrm{W})$ at frequency center $\left(\mathrm{f}_{\mathrm{c}}\right)$. Based on figure 1 , the 2-way WPD has some ideal parameters that can be 
implemented into a microstrip transmission line. Using equation (1) and (2), the width of microstrip line from some ideal parameters of the 2-way WPD can be known [4].

$$
\begin{aligned}
& \epsilon_{r e}=\frac{\epsilon_{r}+1}{2}+\frac{\epsilon_{r}-1}{2}\left(1+12 \frac{h}{W}\right)^{-0.5} \\
& Z_{c}=\frac{120 \pi}{2 \pi \sqrt{\epsilon_{r e}}}\left\{\frac{W}{h}+1.393+0.677 \ln \left(\frac{W}{h}+1.444\right)\right\}^{-1}
\end{aligned}
$$

All physical dimension of microstrip line was obtainable with use LineCalc tools from ADS2011.10 software as presented in Table 1.

Table 1. Ideal Parameters of 2-way WPD.

\begin{tabular}{|c|c|c|}
\hline Parameters & $\begin{array}{c}\text { Impedance } \\
\text { Value }\end{array}$ & $\begin{array}{c}\text { Physical Dimension of } \\
\text { the Microstrip Line (W) } \\
\text { in mm }\end{array}$ \\
\hline$Z_{\mathrm{o}}$ & $50 \Omega$ & 2.40337 \\
\hline$\sqrt{2} * \mathrm{Z}_{\mathrm{o}}$ & $70.7107 \Omega$ & 1.36428 \\
\hline $\begin{array}{c}2 * \mathrm{Z}_{\mathrm{o}} \\
\text { (resistance) }\end{array}$ & $100 \Omega$ & - \\
\hline
\end{tabular}

\section{Simulation and Measurement Result}

The schematic and layout of the 2-way WPD has been designed is shown in Fig. 3. As for the results of the simulation of the 2-way WPD has been designed is shown in Fig. 4. The layout diagram useful for electromagnetic simulation can be generated from the schematic diagram at ADS2011.10 software. The layout diagram was further fine-tuned to improve its performance by changing a length of the $\lambda \mathrm{g} / 4$ transmission line on ADS2011.10 software.
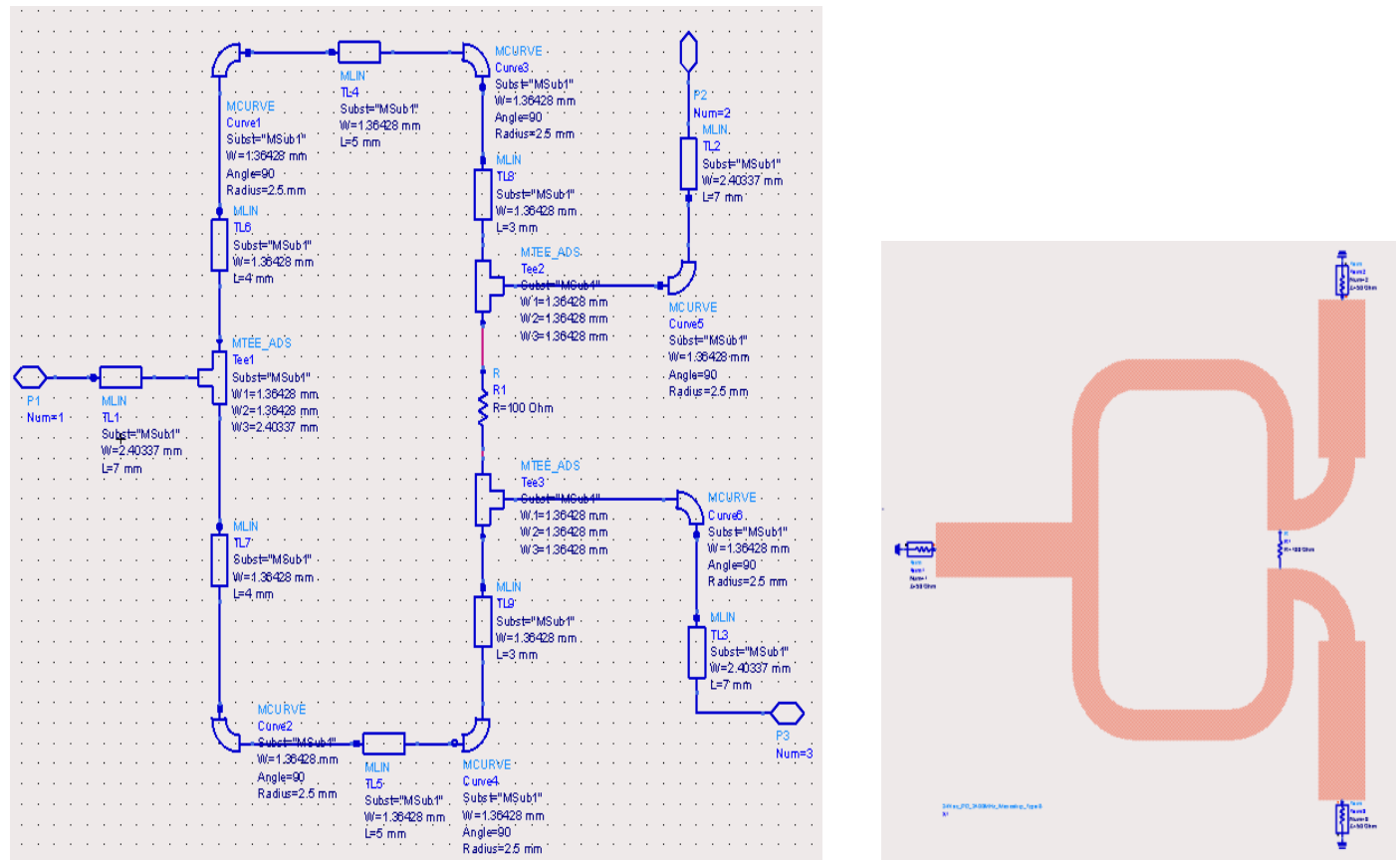

Fig. 3 Schematic and layout diagram for 2-way WPD has been designed.

The result of this simulation contains graphs of the return loss, insertion loss and isolation of the 2-way WPD has been designed as depicted in Fig. 4. For the 2-way WPD, all the ports have excellent well matched with excellent return loss below $-19 \mathrm{~dB}$, this is indicating less than $1.2 \%$ of the power is reflected back. The insertion loss showed that the power divider divides the power equally with transmission loss about $1.96 \%$ at one of the output ports and $1.86 \%$ at the other output ports. So that, the outputs power between the two output ports have a slightly different about $0.107 \mathrm{~dB}$ at frequency center, it's called as amplitude unbalanced. The isolation between the both output ports has good isolations about $-32 \mathrm{~dB}$. 

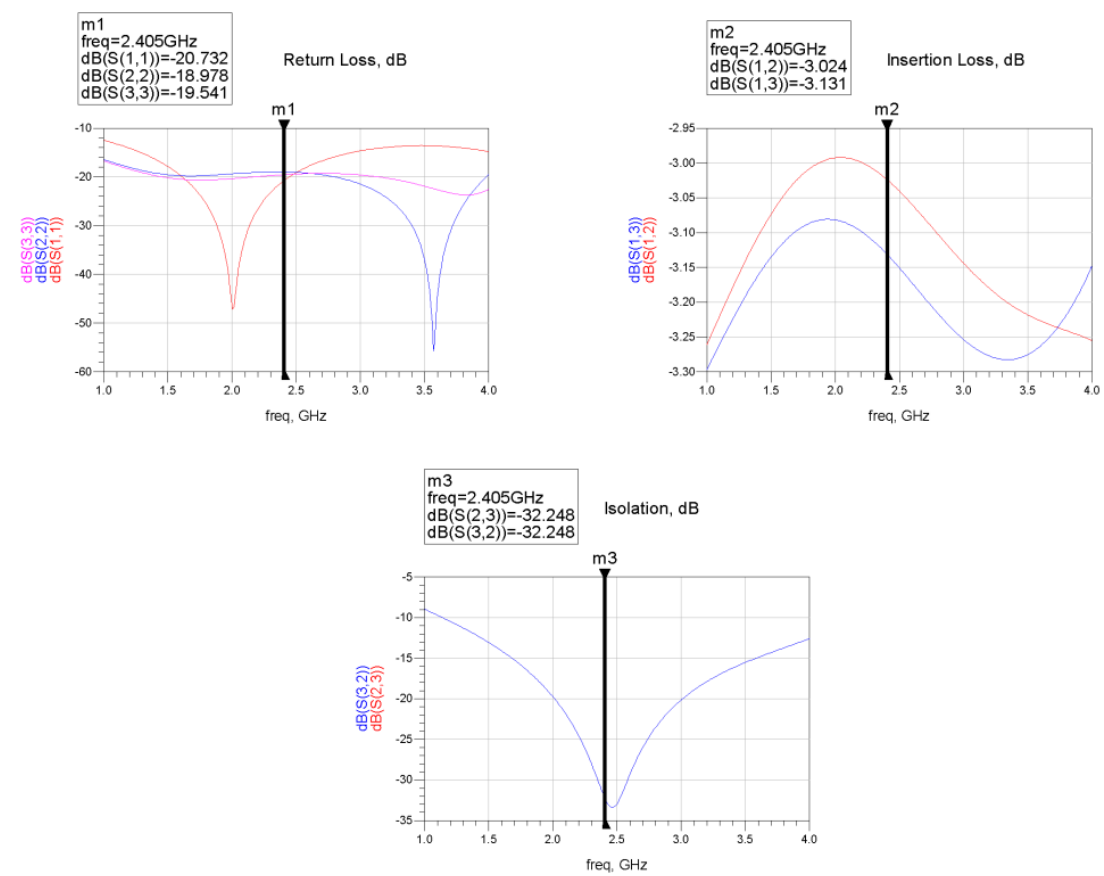

Fig. 4 Simulation Result of 2-way WPD has been designed.

The photograph of the 2-way WPD on Roger Duroid 5580 Substrate is shown in Fig. 5. The 2-way WPD was fabricated use SMA connector at three ports and soldered then a $100 \mathrm{ohm}$ chip resistor placed between the both of output ports.

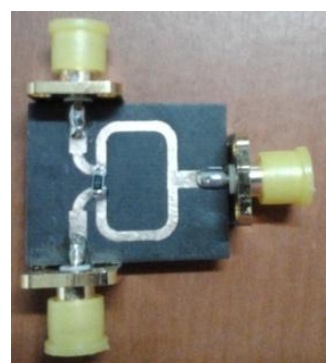

Fig. 5 Photograph of the Fabricate 2-way WPD.

Measurement of the 2-way WPD is done using the Network Analyzer Advantest R3860A which contains charts on voltage standing wave ratio (VSWR), Insertion Loss and Isolation is shown in Fig. 5 until Fig. 7. All ports of the 2-way WPD have an excellent well matched with excellent VSWR value below 1.09. It shows all the ports of the 2-way WPD have reflected power under $0.184 \%$. But from all the ports of the 2-way WPD, port 2 have a good VSWR value than other ports, it's about 1.047.

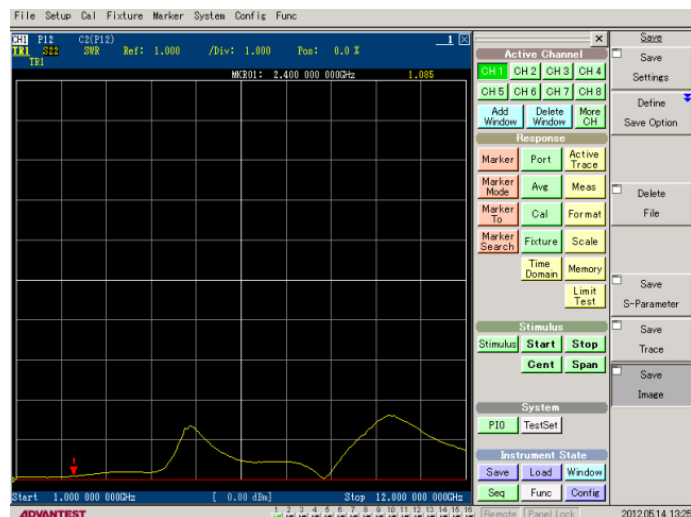

(a)

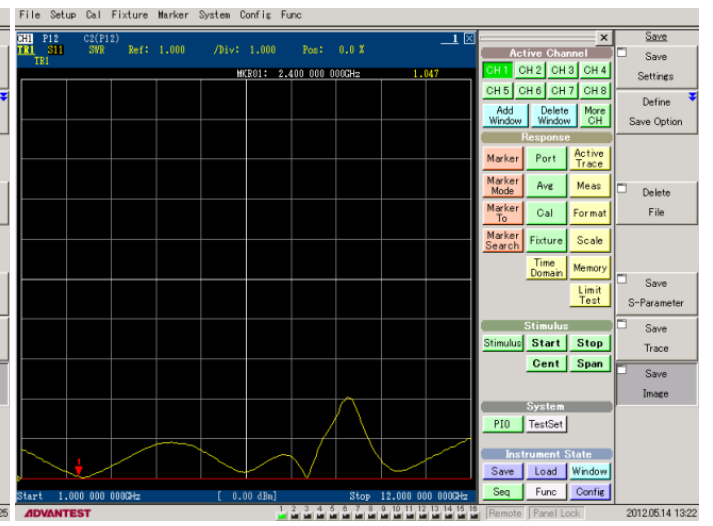

(b) 


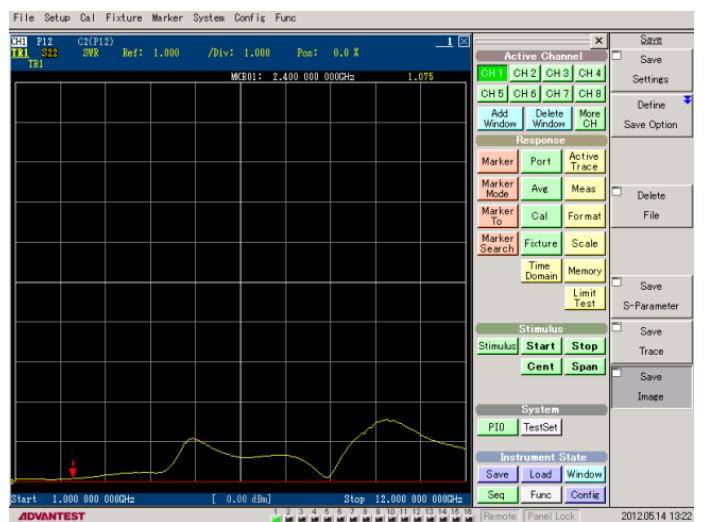

(c)

Fig. 5 Measurement result of VSWR for 2-way WPD.
(a). S11
(b). S22
(c) S33

In Fig. 6, the measurement results of insertion loss showed that the both output ports divides the power equally with transmission loss about $2.07 \%$. The amplitude unbalanced between the both output ports has a different value about $0.284 \mathrm{~dB}$, it causes the amplitude value of the output power between the both outputs ports will be different at measurement frequency center $2400 \mathrm{MHz}$. Actually in data specification of component power dividers from manufacturing, the amplitude unbalance usually maximum about $0.3 \mathrm{~dB}$.

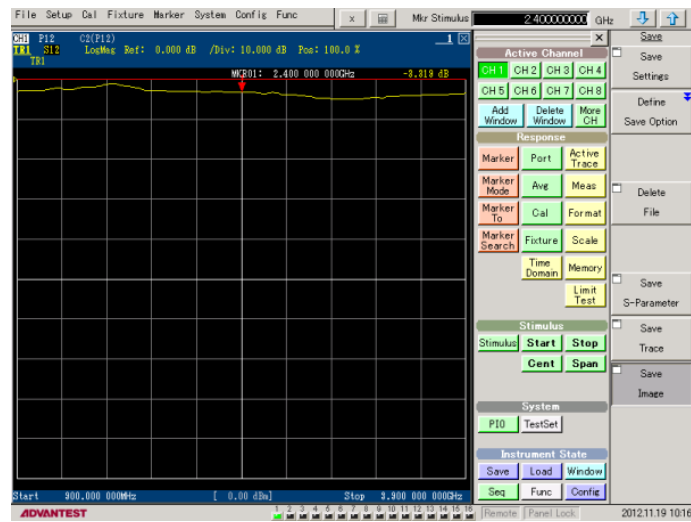

(a)

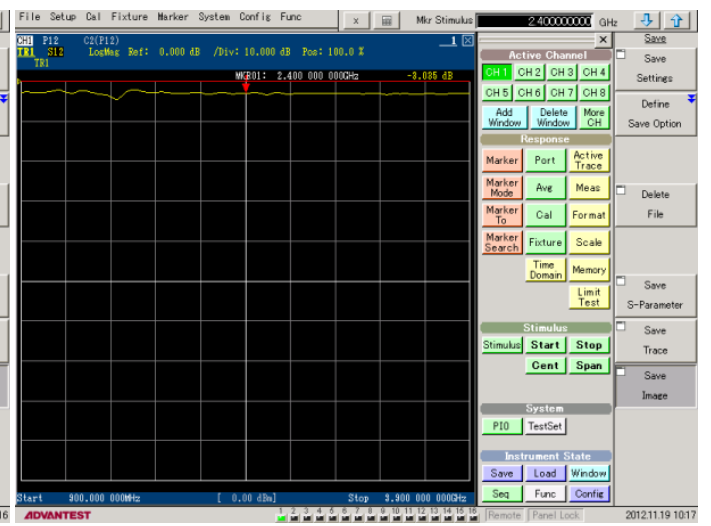

(b)

Fig. 6 Measurement result of Insertion Loss for 2-way WPD.
(a) $\mathrm{S} 12$
(b) $\mathrm{S} 13$

The isolation port of the 2-way WPD has a good isolation approximately $-18.225 \mathrm{~dB}$ (as shown in Fig. 7). Its mean that the both of output port (port 2 and port 3) have only transmitted signal about $0.068 \%$.

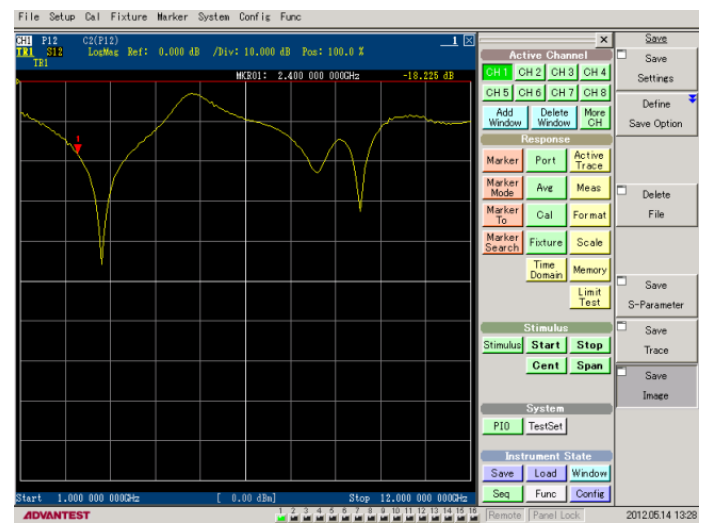

Fig. 7 Measurement result of Isolation (S23) for 2-way WPD.

Based on table 2, the 2-way WPD was designed and fabricated has a great value of insertion loss and VSWR than the 2-way power dividers (PD) wideband from manufacturing. In the other side, the 2-way WPD has worse 
isolation than the 2-way PD wideband, its different until -16.3dB. But it's enough for isolated signal between the both output ports. From the all comparison between the two types, the 2-way WPD can be used in radar system to replacing the 2-way power dividers wideband from manufacturing.

Table 2. Comparison between 2-way WPD has been designed and 2-way PD wideband from manufacturing.

\begin{tabular}{|l|c|c|}
\hline \multicolumn{1}{|c|}{ Parameters } & $\begin{array}{c}\text { 2-way WPD has } \\
\text { been designed }\end{array}$ & $\begin{array}{c}\text { 2-way PD wideband } \\
\text { from manufacturing }\end{array}$ \\
\hline Insertion Loss, & & \\
dB & -3.319 & -3.460 \\
- S12 & -3.035 & -3.411 \\
- S13 & & \\
\hline VSWR & 1.085 & 1.261 \\
- S11 & 1.047 & 1.412 \\
- S22 & 1.075 & 1.413 \\
- S33 & -18.225 & -34.492 \\
\hline Isolation, dB & & \\
\hline
\end{tabular}

\section{Conclusion}

The 2-way WPD has been successfully designed, simulated and fabricated. The 2-way WPD has a good measurement value of insertion loss and VSWR than the 2-way power dividers wideband from manufacture. But in the isolation measurement value from the 2-way WPD has a worse than the 2-way power dividers wideband. The 2-way WPD can be used for divide the power signal from oscillator radar and replacing the 2-way power dividers wideband currently.

\section{Acknowledgements}

This project was supported by RADAR project on Research Center for Electronics and Telecommunication - Indonesian Institute of Sciencies (PPET-LIPI).

\section{References}

[1] Daniel D. Harty, Novel Design of a Wideband Ribcage-Dipole Array and Its Feeding Network, Master Thesis, Worcester Polytechnic Institute, 2010.

[2] Huang Guangpu, Qing Songlin, Fu Jeffrey, Kwang Lee Ching, Design of Narrowband and Broadband Wilkinson Power Divider, Design and Innovation Project, Nanyang Technological University.

[3] David M. Pozar, Microwave Engineering (John Wiley \& Sons Inc, New York, 2005).

[4] Jia-Sheng Hong, M. J. Lancaster, Microstrip Filters for RF/Microwave Application (John Wiley \& Sons Inc, New Jersey, 2011). 